\title{
PENGEMBANGAN AUGMENTED REALITY SEBAGAI MEDIA PEMBELAJARAN PENGENALAN KOMPONEN PNEUMATIK DI SMK
}

\author{
IImawan Mustaqim 1), Nanang Kurniawan') \\ ${ }^{1}$ Fakultas Teknik, Universitas Negeri Yogyakarta \\ email: ilmawan@uny.ac.id \\ ${ }^{2}$ Fakultas Teknik, Universitas Negeri Yogyakarta \\ email:nanangkur93@gmail.com
}

\begin{abstract}
Abstrak
Guru kesulitan menyampaikan materi apabila sekolah tidak memiliki benda sesungguhnya yang digunakan sebagai praktikum. Pneumatik menjadi pelajaran wajib di SMK jurusan teknik mekatronika dan teknik otomasi. Pneumatik sering digunakan dalam industri manufaktur. Tujuan dari penelitian adalah menghasilkan rancang bangun dan unjuk kerja augmented reality sebagai media pembelajaran. Metode pengembangan yang digunakan adalah ADDIE adaptasi dari William W. Lee dan Diana L. Owens yang meliputi 1) analisis, 2) perencanaan, 3) pengembangan dan implementasi, dan 4) evaluasi. Hasil dari rancang bangun berupa aplikasi Pneumatik AR dan Marker AR. Layout disusun menggunakan software CorelDraw X7, sedangkan model 3D dibuat menggunakan bantuan software Blender 3D. seluruh bahan disatukan menggunakan software Unity 3D dengan bahasa pemrograman C\#. Hasil unjuk kerja diperoleh bahwa aplikasi dapat berjalan dengan baik pada beberapa merk dan type smartphone yang digunakan untuk pengujian. Terdapat beberapa kesalahan penampilan gambar 3d pada beberapa marker dengan perbedaan yang kurang spesifik.
\end{abstract}

Kata kunci: media, pembelajaran, augmented reality, SMK

\begin{abstract}
Teachers difficulty delivering material if the school doesn't have the actual object used as a practicum. Pneumatics became a compulsory subject in SMK majoring in mechatronic engineering and automation engineering. Pneumatics is often used in manufacturing industries. The purpose of the research is to produce the design and performance of augmented reality as a learning medium. The development method used is ADDIE adaptation from William W. Lee and Diana L. Owens which includes 1) analysis, 2) planning, 3) development and implementation, and 4) evaluation. Results of the design are application Pneumatic AR and Marker AR. The layout was built by CorelDraw X7 software, while 3D models are created using the help of Blender $3 D$ software. All materials put together using Unity $3 D$ software with $C$ \# programming language. Performance results obtained that the application can run well on some brands and type of smartphone used for testing. There are some $3 d$ image display errors on some markers with less specific differences.
\end{abstract}

Keywords: media, learning, augmented reality, SMK

\section{PENDAHULUAN}

Perkembangan ilmu pengetahuan dan teknologi ikut mendorong perkembangan peralatan yang digunakan di industri. Peralatan produksi yang semula menggunakan sistem konvensional diganti dengan peralatan yang lebih modern, dengan penggantian tersebut diharapkan dapat memaksimalkan hasil produksi dengan menekan biaya operasional produksi. Beberapa industri yang sudah menggunakan peralatan modern dalam proses produksi adalah perakitan kendaraan bermotor, pengemasan makanan dan minuman, serta industri pembuatan peralatan elektronik. Perkembangan ini tentunya harus diikuti dengan peningkakatan kemampuan operator maupaun teknisi dari peralatan tersebut. SMK sebagai sekolah kejuruan yang mencetak lulusan siap bekerja langsung di industri, sudah seharusnya memberikan bekal yang cukup kepada siswa untuk dapat terjun di dunia industri. Keterampilan dasar yang paling sering digunakan di industri diberikan lebih intensif, agar siswa dapat fokus terhadap hal 
yang dipelajari. Salah satu ketrampilan yang digunakan di instrustri adalah teknologi pneumatik.

Pneumatik merupakan salah satu mata pelajaran wajib bagi siswa SMK jurusan Teknik Mekatronika maupun Teknik Otomasi Industri. Penumatik adalah sistem penggerak yang memanfaatkan udara bertekanan sebagai tenaga penggerak. Pneumatik banyak diterapkan di dunia industri, khususnya industri yang bergerak dalam bidang produksi, seperti industri perakitan mobil, pengemasan makanan, dan perakitan sepeda motor. Oleh karena itu, pelajaran penumatik sangat penting sebagai bekal keterampilan siswa. Pengenalan komponen pneumatik menjadi dasar untuk dapat memahami materi pneumatik lebih lanjut. Bagi SMK yang telah memiliki fasilitas laboratorium pneumatik, sangat mudah tentunya bagi guru untuk menerangkan kepada siswa, karena dapat mengambil contoh benda di laboratorium. Berbeda dengan SMK yang belum memiliki fasilitas laboratorium pneumatik. Guru akan lebih sulit untuk menerangkan kepada siswa tentang berbagai macam komponen penumatik dan penggunaannya. Guru bukan menjadi sumber belajar utama bagi siswa, meskipun peranan, tugas, dan fungsi guru tidak dapat dipungkiri dalam proses pembelajaran. Media pembelajaran menjadi hal yang sangat dibutuhkan dalam menerangkan berbagai komponen pneumatik dan cara kerjanya.

Media berperan sebagai alat bantu yang digunakan guru untuk menyampaikan materi supaya lebih mudah dimengerti siswa. Media adalah perantara atau penghantar pesan dari pengirim kepada penerima (Sanaky, 2013:13). Media merupakan instrumen untuk menyederhanakan proses penyampaian pesan dan informasi dari materi (Fajaryati dkk., 2016:192). Pembelajaran adalah proses bertukar informasi antar guru dan siswa yang dilakukan selama kegiatan pembelajaran. Pembelajaran adalah pengembangan pengetahuan baru, kemampuan, atau sikap sebagai individu yang berinteraksi dengan informasi dan lingkungan (Heinich, 2002:6). Pembelajaran merupakan kegiatan yang disengaja direncanakan oleh guru untuk memberikan pengalaman belajar kepada peserta didik dengan tujuan agar peserta didik mampu belajar secara mandiri (Sukoco $d k k$, 2014:2016). Berdasarkan beberapa pengertian tersebut, maka dapat ditarik kesimpulan bahwa media pembelajaran dapat menjadi alat bantu untuk menyampaikan informasi materi dari guru kepada siswa guna merangsang pikiran, perasaan, perhatian, dan kemauan siswa untuk belajar.

Kriteria pemilihan media bersumber dari konsep bahwa media merupakan bagian dari sistem instruksional secara keseluruhan (Arsyad, 2013:74-76). Beberapa kriteria yang sepatutnya diperhatikan dalam pemilihan media adalah (1) Sesuai dengan tujuan yang ingin dicapai. (2) Tepat untuk mendukung isi pelajaran yang sifatnya fakta, konsep, prinsip atau generalisasi. (3) Praktis, luwes dan bertahan, media yang baik dipilih sebaiknya dapat digunakan dimanapun, kapanpun, dan oleh siapapun. (4) Guru terampil menggunakannya. Guru dapat memanfaatkan media dengan baik. (5) Pengelompokan sasaran. Media belum tentu efektif untuk semua kelompok, ada media yang efektif untuk kelompok besar belum tentu efektif untuk kelompok kecil. (6) Mutu teknis. Pemilihan media sebagai alat bantu pembelajaran harus memperhatikan beberapa kriteria. Pada dasarnya media harus efektif, efisien serta tepat sasaran, sehingga tidak membebankan guru maupun siswa dalam kegiatan belajar mengajar. Salah satu pengembangan media pembelajaran yang dapat diterapkan untuk menerangkan pengenalan komponen pneumatik dan fungsinya adalah augmented reality.

Augmented reality apabila diartikan kedalam Bahasa Indonesia adalah "realitas tertambat". Augmented reality adalah proyeksi materi hasil pengolahan komputer, seperti tulisan, gambar, dan video ke dalam perspektif manusia di dunia nyata (Yuen, 2011:120). Secara sederhana augmented 
reality dapat diartikan sebagai penambahan obyek maya pada obyek nyata pada waktu yang sama, sehingga kedua obyek seolah menyatu.

Augmented reality bekerja dengan menggunakan teknik komputer vision dan teknik pattern recognition. Teknik komputer vision merupakan teknik yang dilakukan sistem untuk mencari kartu (marker) (Fernando, 2013:3). Sedangkan teknik pattern recognition adalah teknik untuk mengenali pola yang ada. Maka prinsip kerja augmented reality adalah dengan menambahkan atau mengurangi obyek nyata. Kamera akan mendeteksi obyek nyata dan marker, kemudian informasi akan diteruskan ke sistem grafis. Selanjutnya marker diolah untuk dicocokan dengan data yang sudah tersimpan sebelumnya. Ketika data yang disimpan sesuai dengan marker, obyek maya akan ditampilkan melalui proses rendering. Pada akhirnya obyek maya muncul pada layar monitor yang seolah menyatu dengan obyek nyata.

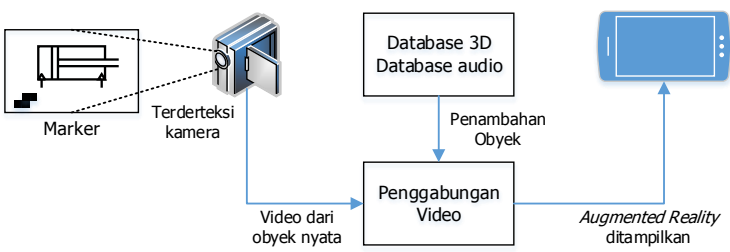

Gambar 1. Proses kerja augmented reality

Berdasarkan uraian di atas terdapat permasalahan SMK sebagai sekolah kejuruan harus menyiapkan lulusan yang berkompeten di bidang teknologi sesuai dengan perkembangan teknologi pneumatik. Dalam mewujudkan lulusan yang kompeten dalam bidang pneumatik dibutuhkan guru yang dapat menyampaikan materi dengan baik. Untuk dapat menyampaikan materi pengenalan komponen pneumatik dengan baik dibutuhkan media pembelajaran yang dapat menjangkau seluruh siswa.

Augmented reality dapat menjadi alternatif untuk digunakan sebagai media pembelajaran pengenalan komponen pnaumatik dan fungsinya. Augmented reality dibungkus pada sebuah aplikasi yang dipasang pada smartphone sehingga dapat menjangkau seluruh siswa yang mayoritas saat ini sudah memiliki smartphone sendiri. Aplikasi pneumatik AR dikemas secara interaktif sehingga siswa dapat berinteraksi dengan media pembelajaran yang digunakan. Tujuan yang ingin dicapai dalam penelitian ini adalah menghasilkan rancang bangun dan unjuk kerja augmented reality sebagai media pembelajaran pengenalan komponen pneumatik di SMK.

\section{METODE}

Penelitian ini menggunakan mode penggembangan ADDIE yang diadaptasi dari William W. Lee \& Diana L. Owens. Tahapan yang perlu dilakukan dalam model pengembangan ini meliputi 1) Analysis (analisis), 2) Design (Perencanaan), 3) Development and Implementation (pengembangan dan impelementasi), dan 4) Evaluation (evaluasi).

Tahap analisis silabus pada kompetensi dilakukan untuk menemukan masalah pada kompetensi yang akan coba diberikan solusi melalui pengembangan media pembelajaran. Materi pokok yang terdapat dalam kompetensi dasar menjelaskan macam-macam komponen pneumatik dan cara kerjanya, yaitu: (1) simbol-simbol pneumatik, (2) katuk KKA dan katup satu arah, 3) katup logika dan katup kombinasi, (4) silinder, (5) suction cup dan vacum generator, (6) pengecekan dan perawan. Pada kompetensi menjelaskan perbedaan rangkaian langsung dan tidak langsung rangkaian pneumatik terdapat satu materi pokok, yaitu kontrol langsung dan tidak langsung silinder kerja tunggal dan ganda. Analisis kebutuhan media pembelajaran yang akan dikembangkan berbasis augmented reality, software yang digunakan untuk mengambangkan yaitu Unity 3D. Media pembelajaran yang direncanakan terdapat dua bentuk, yaitu aplikasi augmented reality yang dipasang pada smartphone dan marker komponen pneumatik.

Tahap desain dilakukan perancangan awal media pembelajaran berbasis augmented reality. Kegiatan yang 
dilakukan pada tahap ini meliputi perancangan data, penyusunan struktur navigasi, dan pembuatan desain tampilan.

Tahap pengembangan merupakan tahap untuk mewujudkan rancangan yang telah disusun pada tahap sebelumnya. Produk dikembangkan sesuai dengan rancangan untuk selanjutnya dilakukan validasi oleh ahli materi dan ahli media. Tahap pengembangan produk dilakukan pembuatan layout dari media pembelajaran dan penyusunan algoritma program. Pembuatan layout media pembelajaran menggunakan bantuan software Corel Draw $x 7$ sedangkan untuk menyusun algoritma pemrograman menggunakan software Unity 3D. Produk media pembelajaran telah selesai dikembangkan dan divalidasi oleh ahli baik materi maupun media. Selanjutnya dilakukan implementasi produk media pembelajaran dalam proses pembelajaran secara langsung oleh pengguna.

Tahap evaluasi dilakukan dengan memberikan angket kepada siswa. Aspek penilaian yang diberikan meliputi kualitas teknis, kualitas isi, dan kualitas instruksional.

Penelitian pengembangan media pembelajaran pneumatik berbasis augmented reality dilaksanakan di SMK N 2 Wonogiri. Subjek penelitian ini adalah siswa kelas XI Teknik Mekatronika SMKN 2 Wonogiri. Selain siswa ada subjek tambahan yaitu dosen Jurusan Pendidikan Teknik Elektro FT UNY sebagai validator ahli materi dan ahli media.

Penelitian pengembangan media pembelajaran ini menggunakan kuisioner atau angket untuk mengumpulkan data penelitian. Metode angket digunakan untuk memperoleh data unjuk kerja media pembelajaran. Instrumen penelitian diperlukan guna memperoleh data atau informasi. Instrumen yang digunakan untuk memperoleh data mengenai unjuk kerja media pembelajaran bagi siswa SMK. Unjuk kerja diperoleh menggunakan teknik Blackbox test. Angket black-box test menggunakan checklist dengan jawaban $\mathrm{Ya}$ dan Tidak sebanyak 30 Butir.
Analisis data yang digunakan adalah kuantitatif deskriptif. Data kuantitatif diperoleh dari pengisiang angket black-box oleh para responeden. Data deskriptif diperoleh dari masukan para responden tentang media pembelajaran yang digunakan.

\section{HASIL DAN PEMBAHASAN \\ Rancang Bangun Media Pembelajaran}

Media pembelajaran augmented reality sebagai media pembelajaran pengenalan komponen pneumatik terdiri dari dua produk, yaitu Pneumatik AR dan marker AR. Pembuatan Pneumatik AR yang berupa aplikasi pada smartphone dengan sistem operasi Android, diawali dengan pembuatan antarmuka pengguna dan marker menggunakan bantuan software CorelDraw $\mathrm{X} 7$.

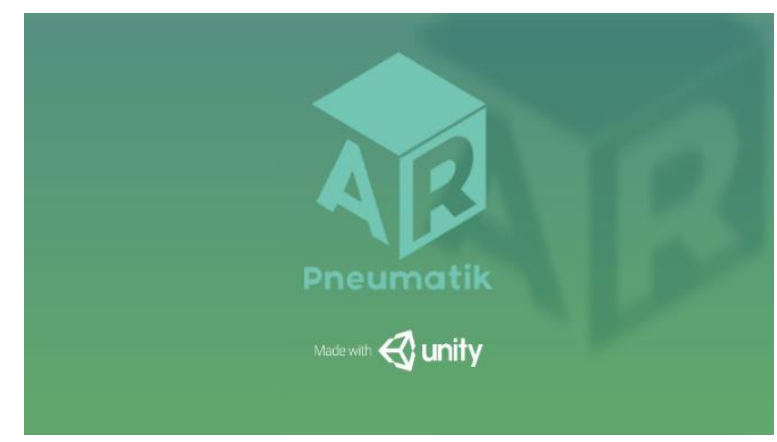

Gambar 2. Tampilan halaman intro

Halaman intro merupakan halaman sebelum masuk ke dalam menu utama pada aplikasi. Halaman intro menampilkan logo aplikasi dan nama aplikasi yang dijalankan.

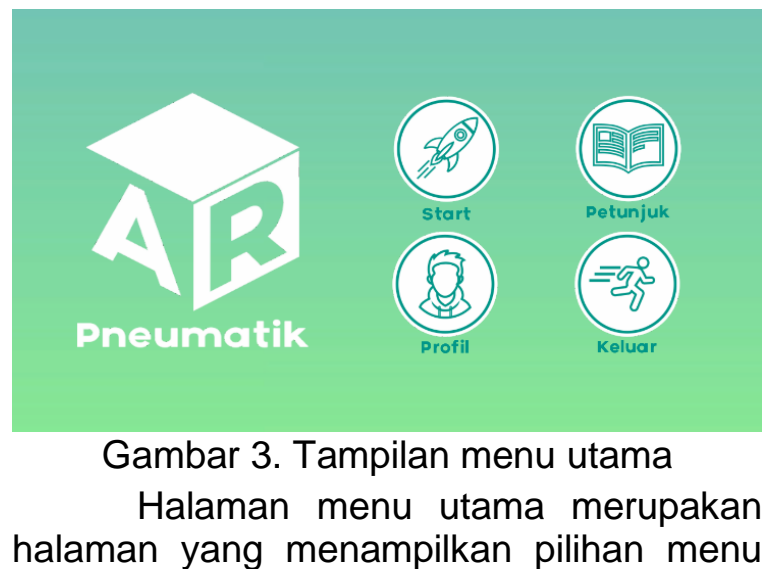


yang dapat diakses oleh pengguna. Pengguna dapat memulai pembelajaran dengan memilih ikon "Start" sehingga masuk pada mode augmented reality.

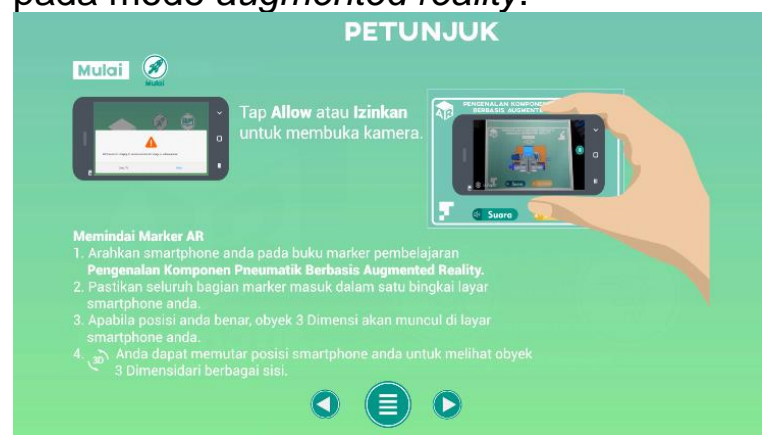

Gambar 4.Tampilan halaman petunjuk

Halaman petunjuk menampilkan petunjuk penggunaan media pemebalajaran. Isi dalam halaman ini adalah petunjuk memulai menggunakan media pembelajaran, petunjuk menggunakan media saat mode augmented reality.

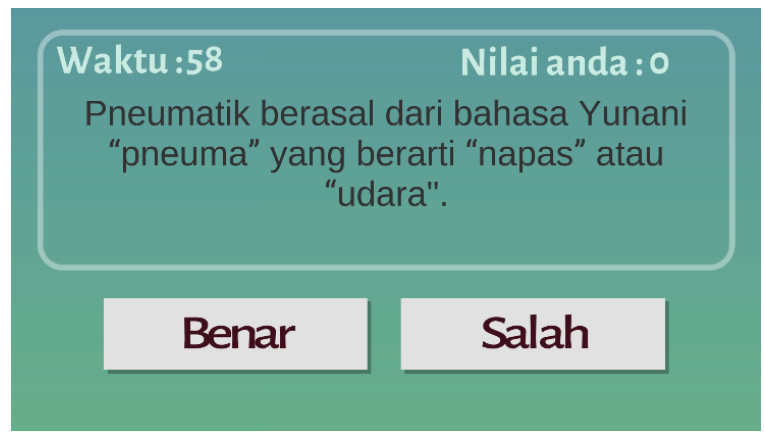

Gambar 5. Tampilan halaman evaluasi

Halaman evaluasi terdiri dari soal seputar materi yang telah dipelajari dalam media pembelajaran. Evaluasi digunakan untuk mengukur tingkat pemahaman siswa terhadap materi yang dipelajari. Soal evaluasi terdari dari 10 soal dengan model Benar Salah. Pengguna dapat masuk ke halaman evaluasi setelah menyelesaikan seluruh pembelajaran.

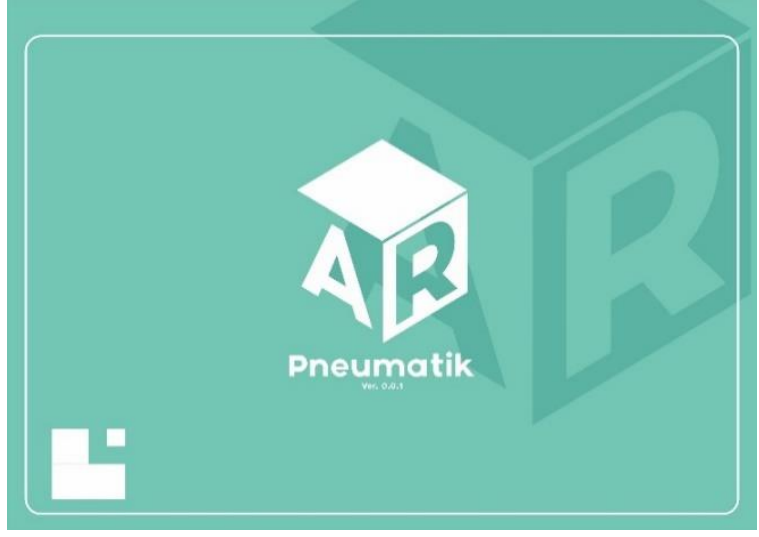

Gambar 6. Halaman muka marker

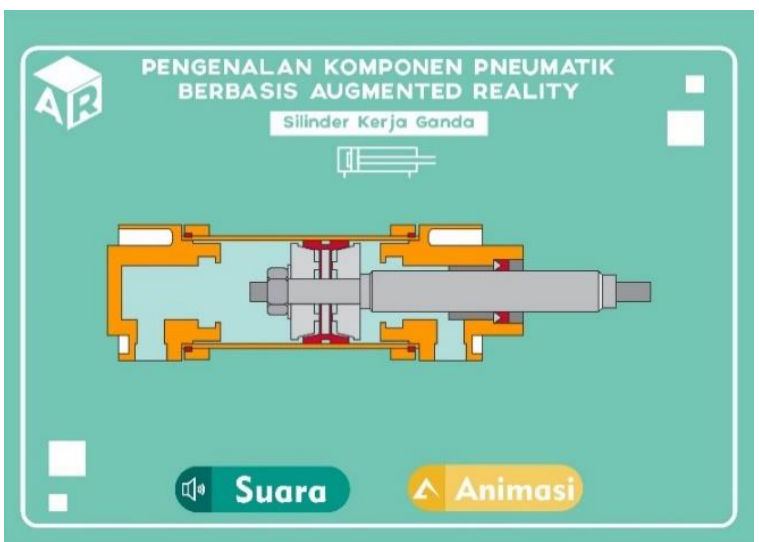

Gambar 7. Marker komponen pnaumatik

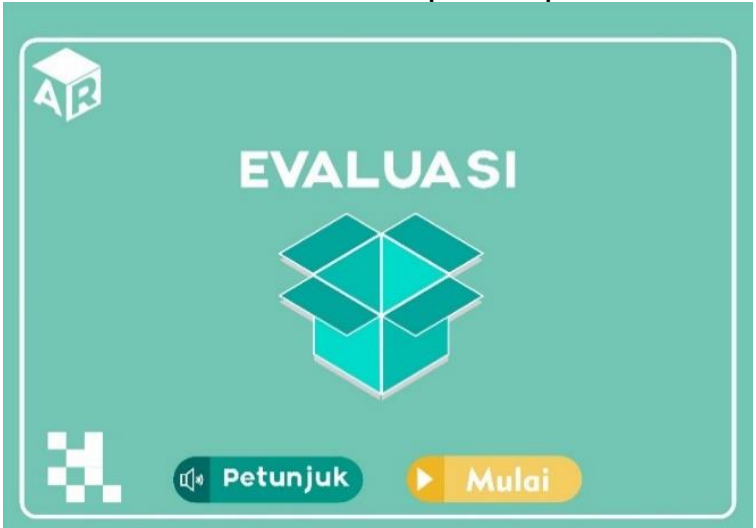

Gambar 8. Marker menuju evaluasi

Marker merupakan sebuah gambar untuk meletakkan obyek dua dimensi maupun tiga dimensi dari sebuah augmented reality. Pada media pembelajaran pengenalan komponen pneumatik berbasis augmented reality, marker berisikan: a) judul media pembelajaran, b) judul komponen pneumatik, c) simbol komponen pneumatik, d) gambar penampang dua dimensi 
komponen pneumatik, e) tombol suara virtual, dan f) tombol animasi virtual.

Pembuatan gambar tiga dimensi serta pemberian animasi menggunakan bantuan software Blender 3D. Di dalam Blender 3D gambar tiga dimensi diberikan warna sekaligus tekstur supaya menyerupai kondisi benda sesungguhnya. Gambar tiga dimensi juga diberikan detail luar dan dalam sehingga pengguna dapat merasakan belajar seperti menggunakan benda aslinya, namun dalam bentuk maya.

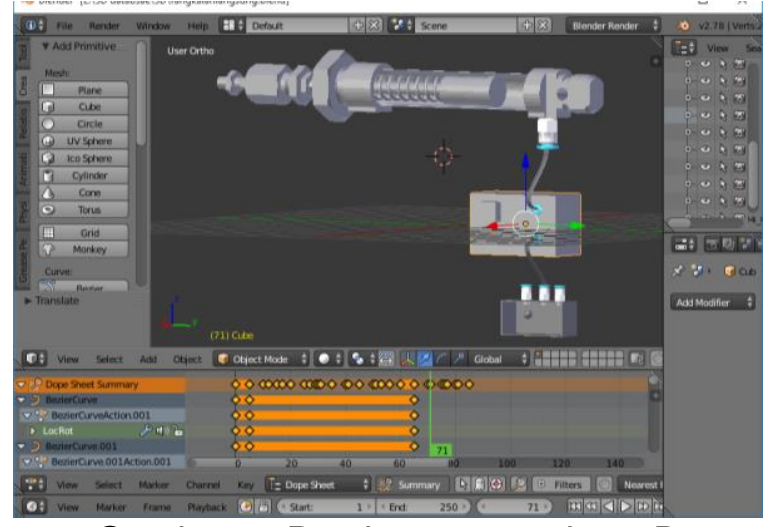

Gambar 9. Pembuatan gambar 3D

Pembuatan aplikasi Pneumatik AR menggunakan bantuan software Unity 3D. Layout antarmuka yang sudah disusun dengan software CorelDraw selanjutnya di ekspor menjadi file dengan ekstensi .jpeg. Gambar tiga dimensi yang telah dibuat menggunakan Blender 3D disimpan dekan ekstensi file .blend. Pada Unity 3D file yang telah diekspor dan disimpan lalu diimpor dalam sebuah project. File disusun sesuai dengan storyboard yang telah disusun. Langkah terakhir adalah implementasi pemrograman. Bahasa pemrograman yang digunakan dalam media pembelajaran ini adalah C\#. Augmented reality disusun dengan memasukkan marker yang telah dibuat kedalam file project Unity 3D. Gambar tiga dimensi diletakkan di atas marker sesuai dengan skema yang terdapat pada marker.

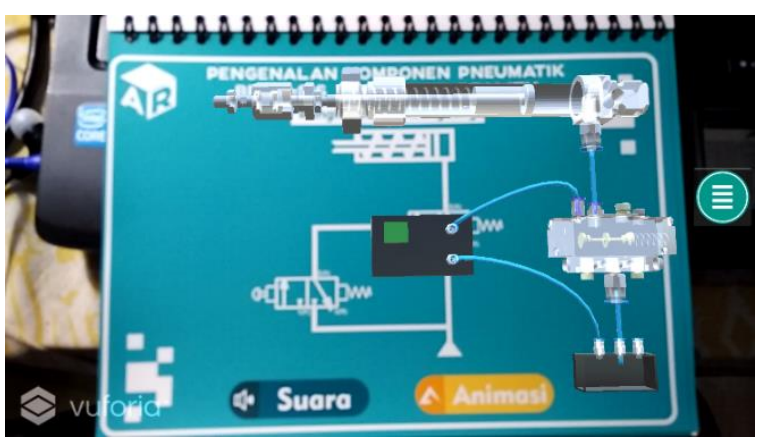

Gambar 10. Tampilan mode augmented reality

Tampilan mode augmented reality menampilkan seperti saat smartphone membuka aplikasi kamera. Pada saat masuk pada mode ini, smartphone diarahkan pada marker AR. Apabila marker dikenali oleh aplikasi maka akan menampilkan gambar tiga dimensi dari komponen pneumatik.

\section{Unjuk Kerja Media Pembelajaran}

Aplikasi Pneumatik AR berekstensi apk yang selanjutnya dipasang pada smartphone dengan sistem operasi Android. Spesifikasi minimal yang harus dimiliki smartphone yaitu sistem operasi minimal Android versi 4.1 (Jelly Bean), memiliki RAM 1024 MB, kamera utama 5 MP, dan ukuran layar 1080x720 pixel. Spesifikasi minimal digunakan untuk menghindari aplikasi berjalan lambat apabila dijalankan pada smartphone di bawah spesifikasi minimum.

Unjuk kerja dilakukan guna mengetahui tingkat kehandalan aplikasi augmented reality sebagai media pembelajaran pengenalan komponen pneumatik. Unjuk kerja dilakukan dengan pengujian black-box untuk menguji fungsi tidaknya aplikasi yang dipasang dalam smartphone dan marker yang dibuat.

Aplikasi media pembelajaran berbasis augmented reality memiliki ukuran 52 Mega Byte. Ukuran aplikasi yang cukup besar dikarenakan di dalam aplikasi terdapat berbagai macam gambar tiga dimensi dari komponen pneumatik yang cukup detail. Meskipun ukuran aplikasi yang cukup besar namun tetap dapat berjalan dengan lancar diberbagai merk smartphone yang digunakan, dengan ketentuan smartphone 
yang memiliki spesifikasi sesuai persyaratan minimum. Ujicoba dilakukan pada smartphone dengan spesifikasi di bawah persyaratan minimum, aplikasi tetap berjalan namun membutuhkan waktu yang relatif lama dalam memproses informasi yang terdapat dalam aplikasi.

Tabel 1. Uji Unjuk Kerja Pada Smartphone

\begin{tabular}{ccccc}
\hline \multirow{2}{*}{ No } & \multirow{2}{*}{ Merk } & \multirow{2}{*}{ Type } & \multicolumn{2}{c}{ Fungsional } \\
\cline { 4 - 5 } & & Ya & Tidak \\
\hline 1 & SAMSUNG & J1 & $\sqrt{ }$ & - \\
2 & ASUS & Zenfone 3 & $\sqrt{ }$ & - \\
3 & XIAOMI & Mi4i, Note3 & $\sqrt{ }$ & - \\
4 & LENOVO & A6000 & $\sqrt{ }$ & - \\
5 & LG & G4 & $\sqrt{ }$ & - \\
6 & SONY & Z1 & $\sqrt{ }$ & -
\end{tabular}

Pada mode augmented reality, beberapa marker dengan perbedaan yang kurang spesifik dengan marker lain, gambar tiga dimensi yang muncul tidak sesuai dengan komponen yang seharusnya muncul. Hal ini disebabkan gambar dua dimensi pada marker kurang beragam, sehingga terdapat kemiripan dengan marker lain. Apabila terjadi hal demikian maka jauhkan marker dari mode augmented reality, kemudian dekatkan lagi sehingga aplikasi akan melakukan pengenalan ulang marker. Dari tahap pengujian tersebut maka dapat dinyatakan aplikasi augmented reality sebagai media pembelajaran pengenalan komponen pneumatik berfungsi dengan baik.

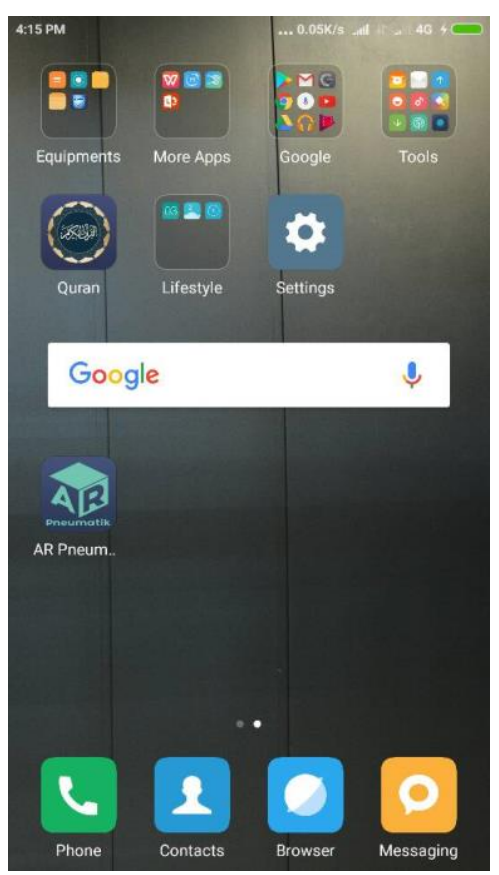

Gambar 11. Pemasangan aplikasi pada smartphone XIAOMI Mi4i 


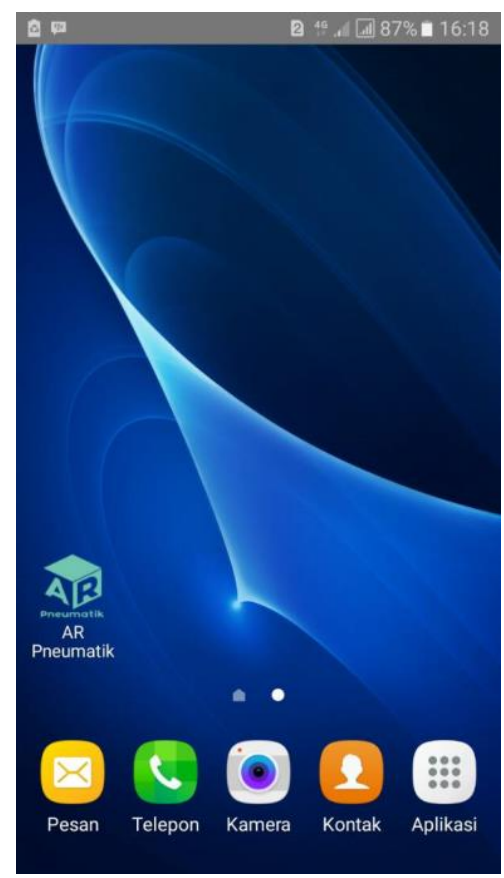

Gambar 12. Pemasangan aplikasi pada smartphone SAMSUNG J1

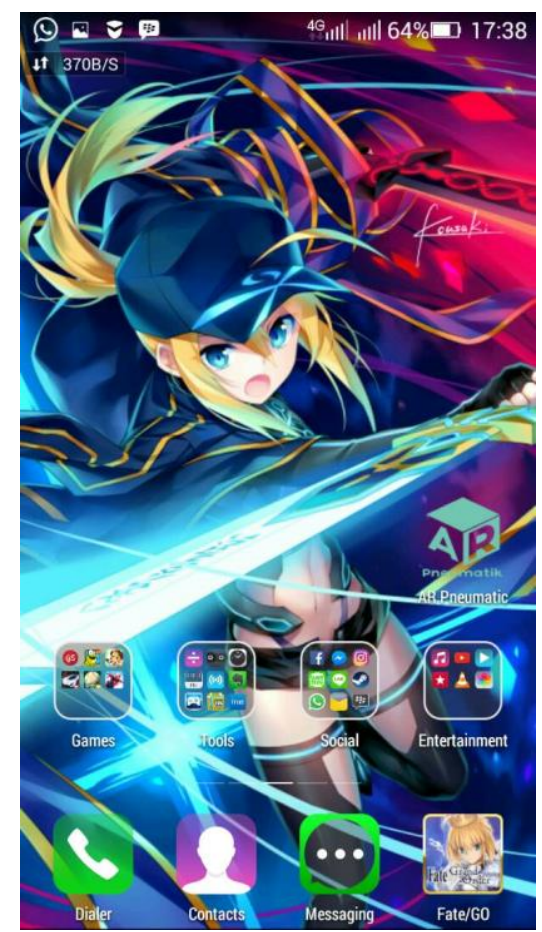

Gambar 13. Pemasangan aplikasi pada smartphone LENOVO A6000

Terdapat dua aspek yang menjadi pengujian dalam black-box test, aspek pemasangan dan aspek pengoperasian. Dari masing-masing aspek diuraikan menjadi indikator yang meliputi 1) pemasangan aplikasi pada smartphone, 2) logo aplikasi muncul pada halaman menu utama smartphone, 3) aplikasi dapat dibuka hingga masuk menu utama, 4) tombol dalam aplikasi dapat digunakan dan halaman yang dituju sesuai dengan ikon, 5) augmented reality dapat berjalan sebagaimana mestinya, dan 6) evaluasi dapat digunakan untuk mengukur tingkat pemahaman pengguna.

\section{SIMPULAN DAN SARAN \\ Simpulan}

Kesimpulan yang dapat diambil berdasarkan data hasil penelitian dan pengembangan augmented reality sebagai media pembelajaran pengenalan komponen pneumatik di SMK diantaranya yaitu:

Pengembangan media pembelajaran menggunakan model pengembangan ADDIE menurut William W. Lee dan Diana L. Owens. Media pembelajaran yang dihasilkan yaitu aplikasi dengan ekstensi apk dan marker AR. Pembuatan layout antar muka menggunakan bantuan bantuan software CorelDraw X7. Pada pembuatan gambar tiga dimensi dan pemberian animasi menggunakan bantuan software Blender 3D. Seluruh bahan yang telah disusun disatukan menggunakan bantuan software Unity 3D dalam sebuah project. Bahasa pemrograman yang digunakan dalam penyusunan media pembelajaran adalah $\mathrm{C \#}$. C\# digunakan karena bahasa yang digunakan mendekati bahasa manusia sehingga lebih mudah dipahami.

$\begin{array}{lcc}\text { Unjuk } & \text { kerja pengembangan } \\ \text { augmented } & \text { reality sebagai media } \\ \text { pembelajaran } & \text { pengenalan komponen }\end{array}$
pneumatik berupa aplikasi Pneumatik AR dan Marker AR dari aspek pemasangan dan pengoperasian. Aplikasi dapat dipasang dan dijalankan pada smartphone yang berbeda-beda. Navigasi pada aplikasi untuk berganti ke halaman lain berfungsi dengan baik. Augmented reality dapat berjalan dengan baik pada tipe smartphone yang digunakan untuk 
pengujian. Gambar tiga dimensi muncul pada saat smartphone diarahkan pada marker. Animasi yang terdapat dalam media pembelajaran dapat berfungsi semua. Aplikasi media pembelajaran dapat digunakan dengan baik pada Android versi Jelly Bean hingga versi Lollipop dengan RAM minimal 1 GB serta ukuran layar 4 inchi hingga 7 inchi. Resolusi tampilan yang digunakan pada media pembelajaran berbasis augmented reality yaitu $1280 \times 720$ pixel dan dapat menyesuaikan dengan ukuran layar smartphone. Pada beberapa marker yang kurang spesifik, gambar tiga dimensi yang muncul terkadang tidak sesuai dengan yang seharusnya. Apabila terjadi hal demikian, jauhkan marker dari smartphone saat mode augmented reality atau sebaliknya, sehingga gambar tiga dimensi komponen pneumatik yang muncul sesuai dengan simbol pada marker.

\section{Saran}

Terdapat beberapa saran untuk mendukung adanya pengembangan augmented reality sebagai media pembelajaran pengenalan komponen pneumatik lebih lanjut dan dapat beroperasi lebih baik lagi.

Pengembangan aplikasi dapat diteruskan dengan mengoptimalkan proses membuka mode augmented reality pada merk smartphone tertentu. Pengembangan aplikasi dapat diteruskan dengan menambah komponen pneumatik. Pengembangan aplikasi dapat diteruskan dengan menambah loading scene untuk mengetahui proses membuka iscene. Pengembangan aplikasi dapat diteruskan dengan membuat marker lebih spesifik.

\section{DAFTAR PUSTAKA}

Arsyad, Azhar. 2014. Media Pembelajaran rev.ed. Jakarta: Rajawali Pers.
Fernando Mario. 2013. Membuat Aplikasi Android Augmented reality Menggunakan Vuforia SDK dan Unity. Solo: Buku AR Online.

Heinich, Robert. et al. 2002. Instructional Media and Technologies for Learning seventh edition. New Jersey: Pearson Education, Inc.

Hujair Sanaky. 2013. Media Pembelajaran Interaktif dan Inovatif. Yogyakarta: PT Kaukaba Dipantara.

Lee, W., W., \& Owens, L., D. 2004. Multimedia-Base Instructional Design. San Francisco: Pfeiffer.

Nuryake Fajaryati. et al. 2016. E-Module Development for The Subject of Measuring Intruments and Measurement in Electronics Engineering Education. Jurnal Pendidikan Teknologi dan Kejuruan: 23(2): 191-199.

Steve Chi-Yin Yuen, Gallayanee Yaoyuneyong dan Erik Johnson. 2011. Augmented reality: On Review an Five Directions for $A R$ in Education. Jurnal Education Technology Development and Exchange: 4(1): 119-140.

Sukoco, Zainal Arifin, dan Muhkamad Wakid. 2014. Pengembangan Media Pembelajaran Interaktif Berbasis Komputer untuk Peserta Didik Mata Pelajaran Teknik Kendaraan Ringan. Jurnal Pendidikan Teknologi Kejuruan: 22(2): 215-226. 